\section{Gaya Kepemimpinan Transformasional, Kompensasi Dan Disiplin Kerja Terhadap Kinerja Karyawan: Mediasi Motivasi Kerja Pada Pertamina Upstream Data Center (PUDC)}

\author{
Kumba Digdowiseiso $^{1}$ dan Nourman Dwi Seftia ${ }^{2}$ \\ Fakultas Ekonomi dan Bisnis, Universitas Nasional \\ Jakarta, Indonesia
}

\begin{abstract}
This study aims to determine and analyze the effect of transformational leadership, compensation and work discipline on employee performance mediated by work motivation at Pertamina upstream data center (PUDC). The sampling method used is cluster random sampling. From a population of 125, all of them were taken as samples for this study. The analytical method used is Path Analysis using AMOS 22 software. The results of this study show that transformational leadership and compensation have a positive and significant effect on work motivation, work discipline has a negative and significant effect on work motivation, transformational leadership, compensation and work discipline have a positive and significant effect. on employee performance, transformational leadership, compensation and work discipline on employee performance mediated by work motivation has a positive and significant effect.
\end{abstract}

Keywords:

Compensation, Employee Performance, Transformational Leadership, Work Discipline, Work Motivation.

\section{Corresponding Author:}

Kumba Digdowiseiso

Fakultas Ekonomi dan Bisnis, Universitas Nasional

Email: kumba.digdo@civitas.unas.ac.id

(C) The Author(s) 2021

DOI: https://doi.org/10.36407/jmsab.v4i2.372
JMSAB

Research Paper

HR Management

Received: 09 Aug 2021

Accepted: 22 Sept 2021

Online: 31 Dec 2021

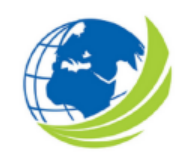

Jurnal Manajemen Strategi dan Aplikasi Bisnis, Vol 4, No. 2, 2021, pp. $533-542$

eISSN 2655-237X

\title{
(C) (2)
}

CC BY: This license allows reusers to distribute, remix, adapt, and build upon the material in any medium or format, so long as attribution is given to the creator. The license allows for commercial use. 


\section{PENDAHULUAN}

Manajemen sumber daya manusia juga menyangkut desain dan implementasi sistem perencanaan, penyusunan karyawan, pengembangan karyawan, pengelolaan karier, evaluasi kinerja, kompensasi karyawan dan hubungan ketenagakerjaan yang baik (Dessler, 2015). Manajemen sumber daya manusia juga melibatkan semua keputusan dan praktik manajemen yang memengaruhi secara langsung sumber daya manusianya. Oleh karena itu penilaian kinerja dilakukan untuk menginspirasi sumber daya manusia (SDM).

Pada konteks ini, kinerja merupakan tingkat pencapaian atau hasil kerja seseorang dari sasaran yang harus dicapai / tugas yang harus dilaksanakan dalam kurun waktu dan di orang tertentu (Arifin 2014). Kinerja dipengaruhi banyak faktor sebagai kendali terhadap faktor tersebut dapat dilakukan dalam mengoptimalkan pencapaian tujuan organisasi.

Pertamina Upstream data centre (PUDC) adalah perusahaan yang bergerak dibidang jasa/ alih media serta menjadi pusat penyimpanan seluruh data kegiatan hulu migas yang berada dibawah Upstream technical centre (UTC). Upstream technical centre (UTC) merupakan anak perusahaan PT Pertamina EP yang bergerak di sektor hulu. Bidang usahanya mencakup kegiatan usaha di sektor hulu bisnis minyak dan gas bumi, meliputi eksplorasi, dan eksploitasi, serta kegiatan usaha penunjang lain yang secara langsung maupun tidak langsung mendukung bidang kegiatan usaha utama ini menjadi pusat penyimpanan seluruh data kegiatan hulu migas baik data primer milik Pertamina maupun data sekunder yang berasal dari berbagai publikasi hasil riset dan kajian lembaga lain yang berbasis pada aktivitas hulu migas dan ilmu serumpun lainnya.

Kinerja karyawan PUDC sudah sangat bagus. Kinerja yang bagus mampu membawa perusahaan kearah tujuan perusahaan ataupun cita - cita perusahaan, sedangkan kinerja karyawan yang buruk akan menghambat pencapaian cita - cita perusahaan. Oleh karena itu peneliti tertarik untuk menelitinya, untuk mengetahui faktor-faktor apa saja yang mempengaruhi kinerja yang baik tersebut. Dari wawancara awal dengan beberapa karyawan menyebutkan kompensasi yang sangat baik, di mana mereka puas dengan kompensasi mereka, dan juga para pemimpin yang inspiratif, dan penerapan disiplin pada pekerjaan yang terus terpantau. Meskipun beberapa kondisi dimana kinerja pegawai tersebut kurang salah satunya adalah keterlambatan masuk jam kerja ataupun jalan - jalan saat jam kerja. Oleh karena itu peneliti bertujuan menguji apakah semua faktor yang disebutkan oleh para karyawan seperti kompensasi, kepemimpinan dan disiplin mampu memotivasi para pegawai PUDC sehingga mampu meningkatkan kinerja mereka menjadi lebih baik. Kontribusi penelitian ini memberikan jawaban dan arahan implikasi praktis kepada perusahaan dalam mempertahankan kinerja yang baik.

Faktor-faktor kinerja yang disebutkan oleh para karyawan PUDC seperti kepemimpinan yang menginspirasi (kepemimpinan transformasional), kompensasi, dan disiplin kerja. Faktorfaktor ini mampu memotivasi dan selanjutnya meningkatkan kinerja sudah banyak dibuktikan oleh beberapa penelitian. Pelaksanaan kepemimpinan yang menginspirasi, perilaku seorang pemimpin yang membuat para pengikutnya mengagumi, menghormati, dan mempercayainya (Sari, 2018) seperti kepemimpinan transformasional (Yanti dan Mursidi, 2021) akan meningkatkan motivasi dan juga meningkatkan kinerja karyawan (Efendi dan Pratama, 2020; Sugiono, 2021; Sari, 2018; Yanti dan Mursidi, 2021). Selain daripada kepemimpinan, peningkatan kinerja karyawan juga didorong oleh adanya pemberian kompensasi yang baik. Peningkatan pemberian kompensasi yang baik akan merangsang untuk para karyawan bekerja lebih baik (Arifudin, 2019; Maharani dan Efendi, 2017). Begitu pula dengan disiplin kerja maka kinerja karyawan juga akan meningkat menjadi lebih baik (Krisnandy dan Nopitasari, 2018; Sinambela dkk., 2021). Maka dari itu penelitian ini bertujuan untuk menguji faktor-faktor yang 
mempengaruhi kinerja yaitu kepemimpinan transformasional, kompensasi, disiplin kerja dengan mediasi motivasi kerja pada karyawan PUDC.

\section{KAJIAN PUSTAKA}

\section{Manajemen Sumber Daya Manusia}

Menurut Handoko (2001:4) :"Manajemen sumber daya manusia adalah penarikan seleksi, pengembangan, pemeliharaan, dan penggunaan sumber daya manusia untuk mencapai baik tujuan individu maupun organisasi". Dari definisi tersebut dapat dilihat pentingnya peranan manajemen dalam mengelola sumber daya manusia yang dimiliki oleh perusahaan atau organisasi untuk mencapai tujuan yang telah ditetapkan oleh perusahaan atau organisasi. Fungsi manajemen sumber daya manusia menurut Hasibuan (2010:21) adalah : Perencanaan (planning), Pengorganisasian (organizing), Pengarahan (directing), Pengendalian (contolling), Pengadaan (procurement), Pengintegrasian (integration), Pemeliharaan (maintenance), Kedisiplinan, Pemberhentian (separation)

\section{Kinerja dan Motivasi kerja}

Pengertian kinerja adalah hasil kerja secara kualitas dan kuantitas yang dicapai oleh seorang pegawai dalam melaksanakan tugasnya sesuai dengan tanggung jawab yang diberikan kepadanya (Mangkunegara, 2011:67). Kinerja adalah penampilan hasil karya personel dalam suatu organisasi. Kinerja dapat merupakan penampilan individu maupun kelompok kerja personel. Penampilan karya tidak terbatas kepada personel yang memangku jabatan fungsional maupun struktural, tetapi juga kepada keseluruhan jajaran personel di dalam organisasi.

Motivasi Kerja menurut Anwar Prabu Mangkunegara (2009:93) dalam Bayu Fadillah, et all (2013:5) "Motivasi adalah suatu dorongan kebutuhan dalam diri pegawai yang perlu dipenuhi agar pegawai tersebut dapat menyesuaikan diri dengan lingkungannya serta mampu mencapai tujuan yang telah ditetapkan. Dengan kata lain, motivasi merupakan sebuah energi untuk membangkitkan dorongan dalam diri guna mencapai tujuan tertentu”. Sedangkan Motivasi menurut Sutrisno (2010:109) dalam Arif Yusuf Hamali, S.S., M.M (2018:133) adalah sebagai berikut :

"Motivasi adalah suatu faktor yang mendorong seseoang untuk melakukan suatu aktivitas tertentu, oleh karena itu motivasi sering kali diartikan sebagai faktor pendorong perilaku seseorang.

H1: Motivasi kerja berpengaruh terhadap kinerja karyawan

\section{Kepemimpinan transformasional, Motivasi dan Kinerja Karyawan}

Istilah kepemimpinan Transformasional (Transformational Leadership) merupakan hasil suatu perkembangan pemikiran beberapa teoritisi kepemimpinan. Diawali dengan pemikiran James Mac Gregor Burns (1979) yang menggunakan istilah transforming leadership (kepemimpinan mentransformasi) kemudian dikembangkan oleh Benard M. Bass (1985) dalam bukunya yang berjudul Leadership and Performance Beyond Expectations yang menggunakan istilah Transformational Leadership (Kepemimpinan Transformasional) yang menurut pengakuan diinspirasi oleh pemikiran Burn. Semejak Bass, istilah transformational leadership merupakan istilah baku dalam ilmu kepemimpinan.

Pemimpin transformasional adalah pemimpin yang mampu mempengaruhi dengan hal yang idealis, menginspirasi sehingga membuat karyawan mengangguminya, mempercayai. Kekaguman dan kepercayaan kepada pemimpin inilah yang membuat para bawahan bergairah dan meningkatkan kinerja mereka (Efendi dan Pratama, 2020; Sugiono, 2021; Yanti dan Mursidi, 
2021). Proses peningkatan kinerja yang dilakukan oleh pemimpin transformasional melalui peningkatan kepercayaan yang mampu memotivasi mereka (Prayudi, 2020).

H2: Kepemimpinan transformasional berpengaruh terhadap kinerja karyawan.

H3: Kepemimpinan transformasional berpengaruh terhadap motivasi kerja.

H4: Kepemimpinan transformasional berpengaruh tidak langsung terhadap kinerja karyawan melalui motivasi kerja.

\section{Kompensasi, Motivasi dan Kinerja Karyawan}

Kompensasi merupakan semua pendapatan yang berbentuk uang, barang langsung, atau tidak langsung yang diterima karyawan sebagai imbalan atas jasa yang diberikan kepada perusahaan (Hasibuan 2012:118). Sedangkan menurut Handoko (2008:115) kompensasi adalah segala sesuatu yang diterima para karyawan sebagai balas jasa untuk kerja mereka. Garry Dessler yang dikutip oleh Yuniarsih dan Suwatno (2009:125) mendefinisikan kompensasi sebagai segala bentuk pembayaran atau imbalan yang diberikan kepada karyawan oleh perusahaan sebagai balas jasa atas kontribusi mereka kepada perusahaan.

Perusahaan yang meningkatkan dan memberikan kompensasi yang baik kepada pekerja akan memilik pekerja yang berkinerja baik (Arifudin, 2019; Maharani dan Efendi, 2017). Penelitian Anggrainy, Darsono dan Putra (2018) mengungkapkan bahwa kompensasi berpengaruh langsung positif terhadap motivasi, kompensasi berpengaruh langsung terhadap prestasi kerja dan kompensasi berpengaruh tidak langsung terhadap prestasi kerja dengan melalui motivasi.

H5: Kompensasi berpengaruh langsung terhadap kinerja karyawan.

H6: Kompensasi berpengaruh langsung terhadap motivasi kerja.

H7: Kompensasi berpengaruh tidak langsung terhadap kinerja melalui motivasi kerja.

\section{Disiplin kerja, Motivasi dan Kinerja Karyawan}

Disiplin kerja adalah suatu alat yang digunakan para manajer untuk berkomunikasi dengan karyawan agar mereka bersedia untuk mengubah suatu perilaku serta sebagai suatu upaya untuk meningkatkan kesadaran dan kesediaan seseorang mentaati semua peraturan perusahaan dan norma-norma yang berlaku (Rivai dan Jauvani, 2009:825). Menurut Davis (dalam Mangkunegara, 2011:129) mengemukakan bahwa disiplin kerja dapat diartikan sebagai pelaksanaan manajemen untuk memperteguh pedoman-pedoman organisasi. Jadi, disiplin kerja merupakan salah satu fumgsi manajemen sumber daya manusia sebagai pedoman dalam melaksanakan tugas-tugas bagi karyawannya.

Pegawai yang disiplin tentunya akan mampu menjaga pekerjaannya terselesaikan tepat waktu. Penyelesaian pekerjaan tepat waktu merupakan salah satu bagian dari penilaian kinerja seorang pegawai. Maka dari itu, disiplin kerja berpengaruh secara langsung terhadap kinerja karyawan (Krisnandy dan Nopitasari, 2018; Sinambela dkk., 2021). Disiplin kerja berpengaruh langsung terhadap motivasi dan berpengaruh tidak langsung terhadap prestasi kerja dengan dimediasi oleh motivasi kerja (Anggrainy, Darsono dan Putra, 2018).

H8: Disiplin kerja berpengaruh terhadap kinerja karyawan.

H9: Disiplin kerja berpengaruh langsung terhadap motivasi kerja.

H10: Disiplin kerja berpengaruh tidak langsung terhadap kinerja karyawan melalui motivasi kerja. 


\section{METODE}

\section{Populasi dan Sampel}

Metode penelitian ini adalah penelitian deskriptif pendekatan kuantitatif dengan metode noneksperimental Penelitian ini merupakan penelitian deskriptif asosiatif, yaitu penelitian yang dilaksanakan untuk mengetahui adanya hubungan antara variabel gaya kepemimpinan transformasional, kompensasi, disiplin kerja, motivasi kerja dan kinerja karyawan. Populasi penelitian ini adalah karyawan PUDC. Peneliti akan menggunakan seluruh jumlah populasi yang ada untuk dijadikan responden yaitu sebanyak 125 responden.

\section{Metode Pengukuran Data}

Semua pengukuran variabel mempergunakan skala likert 1 sampai dengan 5. Skala likert yang menjawab mengenai tingkat persetujuan, dari kategori $1=$ sangat tidak setuju, $2=$ tidaksetuju, $3=$ entral, $4=$ setuju, dan $5=$ sangat setuju. Semua pengukuran telah melalui uji validitas dan reliabilitas.

\section{Metode Analisis}

Metode analisis menggunakan path analysis AMOS 22. Analisis model pengukuran dengan uji kecocokan (GOFI), uji validitas, uji realibilitas hingga analisis pengukuran menyatakan hasil yang cocok (fit).Analisis struktural yang meliputi uji kecocokan keseluruhan model, analisis hubungan kausal dan hasil uji hipotesis.

\section{HASIL DAN PEMBAHASAN}

\section{Instrumen Penelitian}

Semua model pengukuran telah melalui uji validitas dan reliabilitas. Uji validitas mempergunakan analisis faktor. Nilai faktor loading untuk seluruh item telah memenuhi cut of value yaitu di atas 0,5 . Nilai composite reliability juga telah memenuhi, yaitu di atas 0,7 .

\section{Hasil Analisis Model SEM}

Sebelum membahas analisis direct dan indirect effect maka perlu untuk melihat kesesuian model terlebih dahulu. Tabel 1 memperlihatkan hasil kesesuaian model.

\section{Tabel 1. Hasil Uji Kesesuaian Model}

\begin{tabular}{cccc}
\hline $\begin{array}{c}\text { Goodness of } \\
\text { Fit }\end{array}$ & Cut of Value & $\begin{array}{c}\text { Hasil sesudah } \\
\text { modifikasi }\end{array}$ & Keputusan \\
\hline Chi Square & $\leq 190.156$ & 130.134 & Good fit \\
CMIN/DF & $\leq 2,00$ & 0.957 & Good fit \\
P & $\geq 0,05$ & 0.626 & Good fit \\
GFI & $\geq 0,90$ & 0.992 & Good fit \\
AGFI & $\geq 0,90$ & 0.917 & Good fit \\
CFI & $\geq 0,90$ & 1.000 & Good fit \\
TLI & $\geq 0,90$ & 1.007 & Good fit \\
IFI & $\geq 0,90$ & 1.004 & Good fit \\
NFI & $\geq 0,90$ & 0.915 & Good fit \\
RMSEA & $\leq 0,08$ & 0.000 & Good fit \\
\hline
\end{tabular}

Sumber olah data AMOS 22 
Hasil pada tabel 1 menunjukkan bahwa model penelitian ini layak dan baik. Dari semua pengukuran menunjukkan tingkat kelayakan model yang baik. Maka dari itu analisis bisa dilanjutkan.

\section{Hasil Analisis Direct Effect}

Setelah secara keseluruhan sebuah struktural model dapat dianggap fit, proses selanjutnya adalah melihat pengaruh antara variabel independen dengan variabel dependen.

Dasar pengambilan keputusan adalah jika nilai P (Probabilitas) $>0,05$ maka H0 diterima atau tidak ada pengaruh, jika nilai $\mathrm{P}$ (Probalitias) $<0,05$ maka $\mathrm{HO}$ ditolak atau ada pengaruh (Santoso, 2015). Sesuai dengan hasil yang terdapat pada tabel 2, Motivasi kerja berpengaruh positif dan signifikan terhadap kinerja karyawan. Hal ini karena nilai CR sebesar $2.24>1.96$ dan

Tabel 2. Hasil Uji Hipotesis Direct Effect

\begin{tabular}{ccccccc}
\hline Hipotesis & Hubungan & Estimate & S.E. & C.R. & P & Hasil \\
\hline H1 & MK $\rightarrow$ KK & .935 & .417 & 2.244 & $.025^{* *}$ & Diterima \\
H2 & KT $\rightarrow$ KK & .311 & .114 & 2.730 & $.006^{*}$ & Diterima \\
H3 & $\mathrm{KT} \rightarrow \mathrm{MK}$ & .377 & .162 & 2.327 & $.020^{* *}$ & Diterima \\
H5 & $\mathrm{KP} \rightarrow \mathrm{KK}$ & .340 & .089 & 3.806 & $.001^{*}$ & Diterima \\
H6 & $\mathrm{KP} \rightarrow \mathrm{MK}$ & .237 & .108 & 2.203 & $.028^{* *}$ & Diterima \\
H8 & $\mathrm{DK} \rightarrow \mathrm{KK}$ & .315 & .112 & 2.808 & $.005^{*}$ & Diterima \\
$\mathrm{H} 9$ & $\mathrm{DK} \rightarrow \mathrm{MK}$ & -.741 & .289 & -2.561 & $.010^{* *}$ & Diterima \\
\hline * & & & & & &
\end{tabular}

${ }^{*} \mathrm{p}<.01,{ }^{* *} \mathrm{p}<.05$

probabilitas $<0.05$ yaitu 0.025 dan nilai estimate sebesar 0.935 artinya berpengaruh positif dan signifikan. Hasil ini mendukung penelitian terdahulu yang menyatakan meningkatkan motivasi karyawan akan berefek pada peningkatan kinerja karyawan tersebut (Astria, 2018; Apriansyah, Pamungkas dan Wibowo, 2021). Kinerja yang baik tidak akan terjadi tanpa adanya motivasi (Wahyudi, 2019). Karyawan yang termotivasi akan menghasilkan kinerja yang tinggi (Rachman dkk., 2021).

Kepemimpinan transformasional berpengaruh positif dan signifikan terhadap kinerja karyawan. Hal ini karena nilai CR sebesar $2.73>1.96$ dan probabilitas $<0.05$ yaitu 0.006 dan nilai estimate sebesar 0.311 artinya berpengaruh positif dan signifikan. Hal ini mendukung hasil penelitian Apriansyah, Pamungkas dan Wibowo, 2021), bahwa kinerja karyawan terjadi peningkatan ketika gaya pemimpin semakin menerapkan gaya kepemimpinan transformasional.

Kepemimpinan transformational berpengaruh positif dan signifikan terhadap motivasi kerja. Hal ini karena nilai CR sebesar $2.32>1.96$ dan probabilitas $<0.05$ yaitu 0.020 dan nilai estimate sebesar 0.377 artinya berpengaruh positif dan signifikan. Hasil ini membuktikan bahwa kepemimpinan transformasional mampu memotivasi karyawannya (Dwipayana dan Sariyathi, 2018; Prayudi, 2020).

Kompensasi berpengaruh positif dan signifikan terhadap kinerja karyawan. Hal ini karena nilai CR sebesar $3.80>1.96$ dan probabilitas $<0.05$ yaitu 0.001 dan nilai estimate sebesar 0.340 artinya berpengaruh positif dan signifikan. Peningkatan kompensasi yang dilakukan oleh perusahaan akan membawa efek pada peningkatan kinerja karyawan (Nugraha dan Tjahjawati, 2018). Kinerja karyawan dipengaruhi secara positif oleh kompensasi (Arifudin, 2019; Maharani dan Efendi, 2017).

Kompensasi berpengaruh positif dan signifikan terhadap motivasi kerja. Hal ini karena nilai CR sebesar $2.20>1.96$ dan probabilitas $<0.05$ yaitu 0.028 dan nilai estimate sebesar 0.108 artinya berpengaruh positif dan signifikan. Selain mempengaruhi secara langsung terhadap kinerja, kompensasi juga berpengaruh langsung terhadap motivasi (Anggrainy, Darsono dan Putra, 2018). 
Disiplin kerja berpengaruh positif dan signifikan terhadap kinerja karyawan. Hal ini karena nilai CR sebesar $2.80>1.96$ dan probabilitas $<0.05$ yaitu 0.005 dan nilai estimate sebesar 0.315 artinya berpengaruh positif dan signifikan. Karyawan yang disiplin akan menghasilkan kinerja yang lebih baik, semakin disiplin maka kinerja juga semakin baik (Rachman dkk., 2021; Wahyudi, 2019).

Disiplin kerja berpengaruh negatif dan signifikan terhadap motivasi kerja. Hal ini karena nilai CR sebesar $-2.56>1.96$ dan probabilitas $<0.05$ yaitu 0.010 dan nilai estimate sebesar -0.741 artinya berpengaruh negatif dan signifikan. Hasil ini berlawanan dengan beberapa penelitian yaitu disiplin kerja berpengaruh positif terhadap motivasi (Anggrainy, Darsono dan Putra, 2018; Dwipayana dan Sariyathi, 2018). Hal ini perlu kajian lebih dalam. Tetapi mengingat motivasi terbagi menjadi motivasi instrinsik dan ekstrinsik. Sesuai dengan definisi motivasi instrinsik seseorang termotivasi karena kesadaran dalam dirinya sendiri tanpa stimulus dari luar, maka dengan sendirinya seseorang sudah semestinya menyadari akan kedisiplinan. Karyawan yang memiliki motivasi instrinsik akan cenderung tidak menyenangi dengan adanya paksaan. Hal ini akan memberikan arti ketika perusahaan menerapkan tingkat kedisiplnan yang ketat membuat karyawan jengah dan menurunkan motivasi mereka.

\section{Hasil Analisis Indirect Effect}

Hasil analisis uji hipotesis penelitian mengenai pengaruh tidak langsung dilakukan dengan menggunakan Amos 24dan Sobel test. Hasil perhitungan sobel test disajikan pada tabel 3 berikut.

Tabel 3. Hasil Pengujian Indirect Effect

\begin{tabular}{lcc}
\hline \multicolumn{1}{c}{ Hubungan } & Z (C.R.) & P \\
\hline Kepemimpinan transformasional $\rightarrow$ Motivasi $\rightarrow$ Kinerja & 4.242 & 0.002 \\
Kompensasi $\rightarrow$ Motivasi $\rightarrow$ Kinerja & 3.822 & 0.001 \\
Disiplin kerja $\rightarrow$ Motivasi $\rightarrow$ Kinerja & 3.474 & 0.005 \\
\hline
\end{tabular}

Sumber data diolah AMOS 22

Tabel 3 memperlihatkan bahwa kepemimpinan transformasional berpengaruh positif dan signifikan terhadap kinerja karyawan yang dimediasi oleh motivasi kerja. Hal ini karena nilai Z sebesar $4.24>1.96$ dan nilai probabilitas sebesar $0.002<0.05$ artinya berpengaruh positif dan signifikan. Kepemimpinan transformasional mampu mempengaruhi peningkatan kinerja karyawan dikarenakan adanya proses peningkatan motivasi pada diri karyawan (Prayudi, 2020). Pemimpin yang dipercaya, dikagumi dan menginspirasi mampu memotivasi karyawan (Dwipayana dan Sariyathi, 2018) untuk meningkatkan kinerja karyawan tersebut (Nam dan Park, 2019).

Kompensasi berpengaruh positif dan signifikan terhadap kinerja karyawan yang dimediasi oleh motivasi kerja. Hal ini karena nilai Z sebesar $3.82>1.96$ dan nilai probabilitas sebesar 0.001 $<0.05$ artinya berpengaruh positif dan signifikan. Hasil ini mendukung penelitian terdahulu yang mengungkapkan peningkatan kompensasi akan memotivasi karyawan untuk meningkatkan kinerja mereka (Anggrainy, Darsono dan Putra, 2018).

Disiplin kerja berpengaruh signifikan terhadap kinerja karyawan yang dimediasi oleh motivasi kerja. Hal ini karena nilai Z sebesar $3.47>1.96$ dan nilai probabilitas sebesar $0.005<$ 0.05 artinya berpengaruh signifikan. Hasil ini serupa dengan beberapa penelitian terdahulu yang memperoleh hasil yang sama. Disiplin kerja berpengaruh terhadap motivasi (Dwipayana dan Sariyathi, 2018) kemudian hal ini berpengaruh terhadap kinerja karyawan (Anggrainy, Darsono dan Putra, 2018; Rachman dkk., 2021). 


\section{KESIMPULAN DAN IMPLIKASI}

Kepemimpinan transformational berpengaruh positif dan signifikan terhadap motivasi kerja. kepemimpinan transformasional dapat dijadikan acuan untuk meningkat atau menurunnya motivasi kerja. Kompensasi berpengaruh positif dan signifikan terhadap motivasi kerja. kompensasi dapat dijadikan acuan untuk melihat meningkatnya maupun menurunnya motivasi kerja Disiplin kerja berpengaruh negatif dan signifikan terhadap motivasi kerja. disiplin kerja yang semakin meningkat atau menurun tidak dapat dijadikan acuan untuk mengukur motivasi kerja. Kepemimpinan transformasional berpengaruh positif dan signifikan terhadap kinerja karyawan.kepemimpinan transformasional yang ditingkatkan dapat menjadi acuan untuk mengukur peningkatan dari kinerja karyawan. Kompensasi berpengaruh positif dan signifikan terhadap kinerja karyawan. Kompensasi dapat dijadikan acuan untuk mengukur meningkat atau menurunnya kinerja dari karyawan. Begitupula disiplin kerja berpengaruh positif dan signifikan terhadap kinerja karyawan. Disiplin kerja dapat dijadikan acuan untuk mengukur kinerja yang baik maupun buruk. Motivasi kerja berpengaruh positif dan signifikan terhadap kinerja karyawan. Motivasi kerja yang ditingkatkan dapat dijadikan acuan untuk mengukur kinerja dari karyawan.

\section{Keterbatasan dan Saran}

Disarankan agar perusahaan lebih memperhatikan dan mempertahankan kepemimpinan transformasional yang sudah diterapkan di perusahaan karena semakin meningkatnya kepemimpinan akan membuat motivasi kerja dari karyawan semakin meningkat. Kompensasi yang sudah diberikan perusahaan harus lebih ditingkatkan agar motivasi kerja dari karyawan semakin meningkat dan pekerjaan semakin baik. Disiplin kerja yang baik yang sudah diterapkan diperusahaan sebaiknya dipertahankan agar motivasi kerja dari karyawan semakin meningkat dan berdampak baik bagi perusahaan. Kepemimpinan transformasional yang semakin ditingkatkan akan meningkatkan kinerja dari karyawan maka disarankan untuk perusahaan lebih memperhatikan dan mempertahankan kepemimpinan transformasional. Kompensasi yang diberikan perusahaan dipertahankan dan ditingkatkan agar kinerja dari karyawan semakin baik, semakin baiknya kinerja dari karyawan akan berdampak baik bagi perusahaan. Disarankan untuk perusahaan dapat memperhatikan meningkatkan disiplin kerja untuk meningkatkan kinerja karyawan di perusahaan. Motivasi kerja yang baik akan meningkatkan kinerja dari karyawan diharapkan perusahaan memberikan motivasi kerja lebih baik lagi agar kinerja dari karyawan semakin baik. Disarankan untuk perusahaan memperhatikan dan mempertahankan kepemimpinan transformasional terhadap kinerja pegawai agar motivasi kerja juga semakin meningkat dan berdampak baik bagi perusahaan. Disarankan kompensasi yang diberikan perusahaan untuk dipertahankan dan ditingkan terhadap kinerja karyawan agar motivasi dalam bekerja semakin baik. Disarankan untuk perusahaan memperhatikan dan mempertahankan disiplin kerja terhadap kinerja karyawan yang ada diperusahaan agar motivasi kerja dari karyawan dapat meningkat motivasi kerja dan kinerja karyawan yang semakin baik akan berdampak baik bagi perusahaan.

\section{REFERENSI}

Anggrainy, I.F., Darsono, N., \& Putra, T.R.I. (2018). Pengaruh Fasilitas Kerja, Disiplin Kerja Dan Kompensasi Terhadap Motivasi Kerja Implikasinya Pada Prestasi Kerja Pegawai Negeri Sipil Badan Kepegawaian Pendidikan Dan Pelatihan Provinsi Aceh. Jurnal Magister Manajemen Fakultas Ekonomi dan Bisnis UNSYIAH, 2(1). Retrieved from http://202.4.186.66/JMM/article/view/10227

Apriansyah, M., Pamungkas, I. B., \& Wibowo, W.A. (2021). Pengaruh Kepemimpinan Transformasional 
Dan Motivasi Terhadap Kinerja Pegawai Pada Komisi Pemilihan Umum Daerah Kota Tangerang Selatan. Scientific Journal Of Reflection : Economic, Accounting, Management and Business, 4(4), 731-740. Retrieved from https://www.ojspustek.org/index.php/SJR/article/view/377

Arifin, A. (2014). Pengaruh Pemberdayaan Dan Motivasi Terhadap Kinerja Karyawan (Studi Pada Karyawan CV. Catur Perkasa Manunggal)."Jurnal Administrasi Bisnis S1 Universitas Brawijaya 8(2): 79932.

Arifudin, O. (2019). Pengaruh Kompensasi Terhadap Kinerja Karyawan Di Pt. Global Media. Jurnal Ilmiah MEA (Manajemen, Ekonomi, \& Akuntansi), 3(2), 184-190. https://doi.org/10.31955/mea.vol3.iss2.pp184-190

Astria, K. (2018). Pengaruh Disiplin Kerja Dan Motivasi Terhadap Kinerja Karyawan Pada Pt. Bank Rakyat Indonesia Cabang Pamulang. Jurnal Mandiri : Ilmu Pengetahuan, Seni, Dan Teknologi, 2(1), 1-22. https://doi.org/10.33753/mandiri.v2i1.29

Dwipayana, I M G A, dan Sariyathi, Ni K. (2018). Pengaruh Kepemimpinan Transformasional, Disiplin Kerja Dan Komunikasi Terhadap Motivasi Kerja Pada the Jayakarta Bali Beach Resort Residence and Spa Di Kuta Badung. E-Jurnal Manajemen Universitas Udayana 7(6): 2913.

Efendi, S., \& Pratama. (2020). Pengaruh Gaya Kepemimpinan Transformasional Dan Kualitas Kehidupan Kerja Terhadap Kinerja Karyawan Dengan Budaya Organisasi Sebagai Variabel Moderasi Pada Pt Schenker Petrolog Utama Jakarta. Oikonomia: Jurnal Manajemen, 16(2). http://dx.doi.org/10.47313/oikonomia.v16i2.1154

Krisnandy, H., \& Nopitasari, E. (2018). Pengaruh gaya Kepemimpinan Demokratis, Motivasi Intrinsik dan Disiplin Kerja Terhadap Kinerja Karyawan PT Pangansari Utama Food Industry. Oikonomia: Jurnal Manajemen, 14(1). http://dx.doi.org/10.47313/oikonomia.v14i1.511

Maharani, I. \& Efendi, S. (2017). Pengaruh Budaya Organisasi, Komitmen Organisasi, Kompensasi, dan Etos Kerja Terhadap Kinerja Pegawai Kementerian Ketenagakerjaan Republik Indonesia. Oikonomia: Jurnal Manajemen, 13(2). http://dx.doi.org/10.47313/oikonomia.v13i2.505

Nam, K-Ah, \& Park. S. (2019). "Factors Influencing Job Performance: Organizational Learning Culture, Cultural Intelligence, and Transformational Leadership." Performance Improvement Quarterly 32(2): 137-58.

Nugraha, A., \& Tjahjawati, S. S. (2018). Pengaruh Kompensasi Terhadap Kinerja Karyawan. Jurnal Riset Bisnis Dan Investasi, 3(3), 24-32. https://doi.org/10.35313/jrbi.v3i3.942

Pawirosumarto, Suharno, Purwanto Katijan Sarjana, and Rachmad Gunawan. 2017. "The Effect of Work Environment, Leadership Style, and Organizational Culture towards Job Satisfaction and Its Implication towards Employee Performance in Parador Hotels and Resorts, Indonesia." International Journal of Law and Management 59(6): 1337-58.

Prayudi, A. (2020). Pengaruh Gaya Kepemimpinan Transformasional Terhadap Kinerja Karyawan Dengan Motivasi Kerja Sebagai Variabel Intervening (Studi Pada Karyawan Pd. Pembangunan Kota Binjai). Jurnal Manajemen, 6(2). Retrieved from https://www.ejournal.Imiimedan.net/index.php/jm/article/view/128

Rachman, A. ., Fauzi, A. ., Permatasari, S. M. ., \& Darwis, A. . (2021). Pengaruh Kompetensi Guru Dan Disiplin Kerja Terhadap Kinerja Guru Dengan Motivasi Kerja Sebagai Variabel Intervening Di Smk Swasta Kota BekasI. SCIENTIFIC JOURNAL OF REFLECTION : Economic, Accounting, Management and Business, 4(3), 623-632. Retrieved from https://www.ojspustek.org/index.php/SJR/article/view/345

Ramdhani Ghassani Mutiara, Saryadi, Widiartanto. 2015. "Pengaruh Kepemimpinan Transformasional, Disiplin Kerja Dan Budaya Organisasi Terhadap Kinerja Karyawan Pada PT Nasmoco Pemuda Semarang Section Bengkel." Jurnal Administrasi Bisnis 4(3): 79-90. http://garuda.ristekbrin.go.id/documents/detail/1437154.

Sari, S.R. (2018). Konflik dan Kinerja Karyawan. Jurnal Riset Manajemen dan Bisnis (JRMB) Fakultas Ekonomi UNIAT, 3(3).

Sugiono, E. (2021). The Influence of Transformational Leadership, Talent Management, and Employee Placement on Employee Engagement and Its Implications for Employee Performance: Case Study of Premier Bintaro Hospital, South Tangerang City, Indonesia. Dialogos, 25(1), 32-42. https://doi.org/10.4025/dialogos.v25i1.76

Sinambela, S., Naibaho, P., Simanjuntak, E., \& Wijiangkara, G. (2021). Pengaruh Disiplin Kerja, Pelatihan Kerja Dan Motivasi Terhadap Kinerja Karyawan. Jurnal Manajemen Strategi Dan Aplikasi Bisnis, $4(1)$, 
https://ejournal.imperiuminstitute.org/index.php/JMSAB/article/view/279

Tampi, Bryan Johannes. 2014. "Pengaruh Gaya Kepemimpinan Dan Motivasi Terhadap Kinerja Karyawan Pada PT. Bank Negara Iindonesia, TBK (Regional Sales Manado)." Jurnal "Acta Diurna" Volume III. No.4. III(4): 1-20.

Tucunan, Roy Johan Agung, Wayan Gede Supartha, and I Gede Riana. 2014. "Pengaruh Kepemimpinan Transformasional Terhadap Motivasi Dan Kinerja Karyawan (Studi Kasus Pada PT. Pandawa)." EJurnal Ekonomi dan Bisnis Universitas Udayana 3(9): 533-50.

Vijaya, I, and A. Sriathi. 2015. "Pengaruh Kepemimpinan Transformasional, Lingkungan Kerja Fisik Dan Kompensasi Terhadap Kinerja Karyawan Pada Perusahaan Cok Konfeksi Denpasar.” E-Jurnal Manajemen Universitas Udayana 4(7): 255138.

Wahyudi, M. (2019). Pengaruh Disiplin Dan Motivasi Terhadap Kinerja Karyawan. Scientific Journal Of Reflection : Economic, Accounting, Management and Business, 2(3), 351-360. https://doi.org/10.37481/sjr.v2i3.84

Yanti, D. A., \& Mursidi, M. (2021). Pengaruh Kepemimpinan Transformasional Dan Kompetensi Terhadap Kinerja Karyawan. Jurnal Manajemen Strategi Dan Aplikasi Bisnis, 4(1), 23 - 34. https://doi.org/10.36407/jmsab.v4i1.266

\section{Competing interests}

The authors declare that they have no competing interests. 